\title{
Erratum to: To walk or not to walk: insights from a qualitative description study with women suffering from fibromyalgia
}

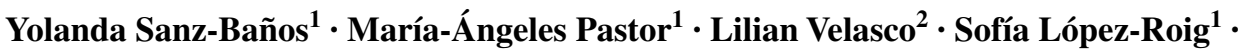 \\ Cecilia Peñacoba $^{2} \cdot$ Ana Lledo $^{1} \cdot$ Charo Rodríguez $^{3}$
}

Published online: 19 April 2016

(C) Springer-Verlag Berlin Heidelberg 2016

\section{Erratum to: Rheumatol Int \\ DOI 10.1007/s00296-016-3459-6}

Two references [28] and [31] were published incompletely in anonymous format. The complete references [28] and [31] are provided here.

\section{References}

28. Pastor M-Á, López-Roig S, Lledó A, Peñacoba C, Velasco L, Schweiger-Gallo I et al (2014) Combining motivational and volitional strategies to promote unsupervised walking in patients with fibromyalgia: study protocol for a randomized controlled trial. Trials 15:120

31. Pastor M-Á, López-Roig S, Sanz Y, Peñacoba C, Cigarán M, Lledó A et al (2015) Walking as physical exercise in fibromyalgia: an elicitation study from the Theory of Planned Behavior. Anales de Psicología 31:433-446

The online version of the original article can be found under doi:10.1007/s00296-016-3459-6.

María-Ángeles Pastor mapastor@umh.es

1 Department of Health Psychology, Miguel Hernández University, Ctra. Alicante-Valencia, km. 8.7, 03550 Alicante, Spain

2 Department of Medicine and Surgery, Psychology, Preventive Medicine and Public Health and Medical Microbiology and Immunology, Faculty of Health Sciences, King Juan Carlos University, Av Atenas, S/N, 28922 Alcorcón, Madrid, Spain

3 Department of Family Medicine, Faculty of Medicine, McGill University, 5858, chemin de la Côte-des-Neiges, 3rd Floor, Montreal, QC, Canada 